\title{
Determination of Anti-Mycoplasma Capricolum Subsp. Capripneumoniae Antibodies For The Sero- Epidemiology of Contagious Caprine Pleuropneumonia
}

\section{Faisal Ahmad}

The University of Agriculture

Farhan Anwar Khan ( $\sim$ farhan82@aup.edu.pk)

The University of Agriculture https://orcid.org/0000-0001-6024-1269

Umer Sadique

The University of Agriculture

Abdul Sajid

Abdul Wali Khan University

\section{Research Article}

Keywords: CCPP, cELISA, Goats, Mccp, Sero-epidemology

Posted Date: February 1st, 2022

DOI: https://doi.org/10.21203/rs.3.rs-1162481/v1

License: (c) (1) This work is licensed under a Creative Commons Attribution 4.0 International License.

Read Full License 


\section{Abstract}

Contagious caprine pleuro-pneumonia (CCPP) is fatal disease of goats and causes huge economic losses due to high morbidity and mortality. CCPP is enlisted as notifiable animal disease by OIE. The causative agent of CCPP is Mycoplasma capricolum subsp. capripneumoniae (Mccp). The present study was aimed to investigate the seroprevalence of CCPP in northern Pakistan. The study areas were divided into three zones; northern zone, central zone and tribal zone. A total of 1300 serum samples were collected during November 2017 - April 2019 from goats of different age and sex and were analysed by monoclonal antibody based cELISA. The analyses revealed 227 (17.5\%) samples positive for anti-Mccp antibodies. The zone wise distribution of CCPP in goats was significantly different (P囚0.05), indicated by positive sera for Mccp of $23 \%$ animals from northern zone followed by $15 \%$ and $13 \%$ animals from tribal and central zones, respectively. The analysis of data showed non-significant values in the seroprevalence among bucks and doe(s), indicated by anti-Mccp sera from $16.6 \%$ bucks and $18.3 \%$ doe (s). Moreover, among different age groups the prevalence of disease in adult goats $(20 \%)$ was significantly (Pख0.05) higher than kids (10.8\%). It is evident from the present study that CCPP caused by Mccp is prevalent in Pakistan and both sex of animals are equally susceptible to Mccp infection. Furthermore the disease is more prevalent in northern zone.

\section{Introduction}

Goats farming in developing countries like Pakistan face several problems including poor husbandry practices, extreme environmental stresses, and deficiency of good quality feed stuff and various types of infectious, parasitic and various other non-corrosive diseases. Among the infectious bacterial diseases, the mycoplasmal diseases are well known all over the world for its pathogenicity and high economic loss directly affecting farmers (Regassa et al., 2010). The prevalence of caprine mycoplasmosis has been documented from different region of the globe, however the occurrence of these diseases is more frequent in Asia and Africa and are considered the major constraint to goat industry in terms of high morbidity and mortality (Tigga et al., 2014; Srivastava et al., 2010). Among various mycoplasmal infections, contagious caprine pleuro-pneumonia (CCPP) is serious threat to goats and their production performance in developing countries (Bascunana et al., 1994; Lorenzon et al., 2002). CCPP was first reported in 1873 in Algeria (McMartin et al., 1980). The causative agent Mycoplasma capricolum subsp. capripneumoniae (Mccp) was first isolated in 1976 (MacOwan, 1976). Mycoplasma capricolum subsp. capripneumoniae belongs to mycoplasma mycoides cluster, a group of five closely related species, pathogenic to ruminant population that includes; Mycoplasma mycoides subsp. mycoides (Mmm), Mycoplasma mycoides subsp. capri (Mmc), Mycoplasma capricolum subsp. capricolum (Mcc), Mccp and Mycoplasma leachii (Fischer et al., 2012). Two members of the group, Mccp and Mmm are responsible for economically dangerous diseases including CCPP and contagious bovine pleuropneumonia (CBPP) respectively. Both are listed by World Organization for Animal Health (OIE) as notifiable diseases. Other member of the $\mathrm{M}$. mycoides cluster $(\mathrm{Mcc}$, and $\mathrm{Mmc}$ ) and non-cluster specie $\mathrm{M}$. putrefaciens are involved to induce manifold pathological condition in small ruminants like mastitis, 
arthritis, keratoconjunctivitis, pneumonia and septicaemia, which is usually term as 'MAKePS' (Thiaucourt and Bolske, 1996).

In Pakistan, Mmc was first detected among Mm cluster by applying various tests on clinical samples from infected goats suspected for CCPP (Khan et al., 1989). In district Pishin of Balochistan, goats flocks were investigated for CCPP based on clinical examinations, by biochemical, growth inhibition and PCR on the collected samples (nasal swabs, lungs, liver, and intestinal tissues), two mycoplasma species i.e. Mcc and Mycoplasma putrefaciens (MP) were found prevalent in the affected goats (Awan et al., 2008). The prevalence of respiratory mycoplasmal infection in different region of Pakistan was reported by late agglutination (LAT) test for Mccp, growth inhibition test (GIT) for Mmc and PCR for Mm cluster and found forty eight samples positive for Mmc on GIT, none of the serum sample was detected positive for Mccp, whereas thirty-five samples were confirmed as Mm cluster by molecular technique (Shahzad et al., 2012). Similarly, Mmc was also found in samples collected from goats having similar signs of CCPP infection in Khyber Pakhtunkhwa (Sadique et al., 2012). However, the first report where the presence of Mccp has been confirmed by PCR in the country was published from district Pishin of Balochistan (Awan et al., 2010). Later on, the molecular prevalence of Mccp was also reported in goats from Khyber Pakhtunkhwa elsewhere (Shah et al., 2016). The sero-prevalence of Mccp was also showed in selected districts of Khyber Pakhtunkhwa and Punjab, Pakistan, by monoclonal antibody-based competitive enzyme-linked immunosorbent assay (cELISA) previously (Wazir et al., 2016; Shahzad et al., 2016). The current distribution of CCPP in many regions of Africa and Asia is not very well known because of scarcity of diagnostic facilities, furthermore for prevalence of CCPP at herd level the World Organization for Animal Health (OIE) prescribed cELISA and CFT (Jores et al., 2020).

Increased interest and view of the above facts there is a dire need for monitoring of mycoplasma related outbreaks and distribution of these economically important diseases. In developed countries like United Kingdom they have national surveillance network which regularly publishes the prevalence results of the economically important diseases (Ayling et al., 2004). Similarly, in France, the French Food Safety Agency (AFSSA) has national surveillance network VIGllance to Mycoplasmoses of ruminants (VIGMYC) in collaborating with different diagnostic laboratories monitoring the prevalence of Mycoplasmosis in the country (Chazel et al., 2010).

This project was designed to investigate the serological prevalence of CCPP the Khyber Pakhtunkhwa Province and northern areas of Pakistan for effective therapeutic interventions and control strategy to prevent CCPP outbreak in goat's population.

\section{Material And Methods}

\subsection{Study Area}

This study was performed across the Khyber Pakhtunkhwa, Gilgit-Baltistan, Pakistan. The selected districts along with tribal districts were divided into three different zones namely, northern zone, central 
zone, tribal zone. Northern zone includes Gilgit-Baltistan, Chitral, Swat, Buner, and Hazara. Central zone includes Charsadda, Mardan, Swabi, Peshawar, and Nowshera districts. The tribal zone includes the tribal districts, Khyber, Bajour, and Mohmand. The climatic condition of the northern zone is extremely cold with heavy rainfall and snowfall in winter season. The weather is pleasant in summer days and extremely cold in winter season. The tribal region containing federally administrated areas (Now part of Khyber Pakhtunkhwa, Province) has borders with Afghanistan and has extreme climate in summer and winter. The climatic condition of the Central zone is hot humid (Fig. 1).

\subsection{Sample size}

A total of 1300 serum samples were collected from goats during November 2017 to April 2019. All the samples were collected based on clinical signs i.e.mucopurulent nasal discharges, productive cough, deep abdominal respiration (Fig. 2), pyrexia $\left(40-41^{\circ} \mathrm{C}\right)$ and history of respiratory infection and no vaccination record against CCPP. The samples were collected from different age and sex groups of animals. The number of samples collected from each zone is presented in (Table 1). The Lab work and analysis of the results were performed in pathology laboratory, College of Veterinary Sciences, Faculty of Animal Husbandry and Veterinary Sciences, The University of Agriculture Peshawar.

\subsection{Harvesting of serum}

The blood samples were collected from the jugular vein of animal's adopting aseptic condition. The blood was poured to gel containing tube and centrifuged for 5 minutes at $5000 \mathrm{rpm}$. The serum was transferred to sterile eppendorf tube in aseptic environment and was stored at $-20^{\circ} \mathrm{C}$ until further processing.

\subsection{IDEXX CCPP Antibody Test}

The serum was subjected to cELISA test for the detection of Mccp specific antibodies. The procedure was performed following the manufacturer instructions (IDEXX). The optical density (OD) values of samples and controls were measured and record at $450 \mathrm{~nm}$ wavelength using the ELISA plate reader.

\subsection{1: Serum samples absorbance (OD value) analysis:}

The absorbance values of Controls, were calculated by the following formulas:

Control mean absorbance (CCx) and Mab Control mean absorbance (MabCx)

$\mathrm{CCx}=(\mathrm{CC} 1 \mathrm{~A}(450)+\mathrm{CC} 2 \mathrm{~A}(450) / 2$

$\operatorname{MabCx}=(\operatorname{MabC} 1 \mathrm{~A}(450)+\operatorname{MabC2} A(450)+\operatorname{MabC} 3 \mathrm{~A}(450)+\operatorname{MabC4} A(450)) / 4$

Samples and Controls

Calculated the percentage of inhibition (S PI) for each sample and Control according to the given formula. 
$\mathrm{S} \mathrm{PI} \%=100 \mathrm{X}((\mathrm{MabCx}-\mathrm{S} \mathrm{A}(450)) /(\mathrm{MabCx}-\mathrm{CCx})$

Validity criteria

$0.500 \leq \mathrm{MabCx} \leq 2.00 \mathrm{CCx}<0.300$

Mean $\mathrm{NC} \mathrm{PI} \leq 35 \% 50 \% \leq$ Mean PC PI $\leq 80 \% 60 \% \leq$ Mean $\mathrm{SPC} \mathrm{PI} \leq 90 \%$

Interpretation

Negative S PI\% < 55\% Positive S PI\% > 55\%

\subsection{Statistical Analysis}

All the data obtained was compiled into the Microsoft Excel spread sheet and analysed through Chi square statistical test. Confidence level was taken at $95 \%$ and $p$ value less than 0.05 for significance in all analysis.

\section{Results}

A total of 1300 samples were collected in different zones including northern, central, and tribal zones from naturally respiratory infected goats which were considered suspected for CCPP. The screening of the samples through monoclonal antibody based cELISA test revealed 227 (17.5\%) samples positive for CCPP.

\subsection{Prevalence of CCPP in different zones}

The region wise prevalence of the disease in goats was recorded as $23 \%$ in northern zone followed by $15 \%$ tribal zone, and $13 \%$ central zone. The analysis of the data through Chi square statistical test revealed significantly difference (Pख0.05), in the prevalence of disease, among different zones of the studied areas (Table 2).

\subsection{Gender based prevalence of CCPP in different zones}

Out of total 1300 samples, 650 serum samples were collected from bucks and 650 from Doe(s). The processing of the samples by cELISA revealed 108 (16.6\%) male and $119(18.3 \%)$ female goats positive for anti-Mccp antibodies. The analysis of the data by Chi square test revealed non-significant difference $(P>0.05)$, in the prevalence of disease, between different sexes of goats (Table 3).

\subsection{Age wise prevalence of CCPP in goats}

Out of 900 samples collected from adult goats having age above 180 days, the anti-Mccp antibodies by cELISA were observed in 184 (20\%) samples. While in young animals (age: day1 up to 6 months), 43 (10.8\%) samples revealed reactive antibodies against Mccp pathogen. The prevalence was significantly (P囚0.05) different recorded between different age group of animals (Table 4). 


\subsection{District wise prevalence of CCPP in studied area}

In the northern zone the highest prevalence of the disease was found in animals from Gilgit Baltistan (27.4\%), followed by animals from Chitral, Hazara, Buner and Swat $24.4 \%, 23 \%, 19.7 \%$, and $16.8 \%$ respectively (Table 5).

The central zone is divided into 05 districts (Charsadda, Mardan, Swabi, Peshawar, Nowshera). The prevalence of Mccp recorded in the present study was higher in Charsadda 17.5\% followed by Mardan, Swabi, Nowshera and Peshawar 15\%, 13.7\%, 11.2\% and 7.5\% respectively. The lowest occurrence of the disease was recorded in District Peshawar (Table 6). In tribal zone the maximum frequency of occurrence of the CCPP was recorded in tribal district Khyber (18.6\% and tribal district Bajour (14\%), while the lowest occurrence of the disease was noted in tribal district Mohmand (11\%) (Table 7).

\section{Discussion}

In the livestock population of Pakistan, goats keep a great importance as it contributes the highest number of 78 million heads (Pakistan Economic Survey 2017-18). The majority of the small poor farmers are solely depended on goats population where rearing of cattle is difficult, due to its great influence on the livelihood of poor farmers, it is also known as poor's man cow in Pakistan (Rahman et al., 2003).Among the fatal infectious diseases mycoplasmosis is a severe threat to small ruminant directly impact farmer's economy (Regassa et al., 2010). Caprine mycoplasmosis has been documented across the globe, however the frequency of the infection is higher in underdeveloped countries of Africa and Asia and cause huge economic losses (Srivastava et al., 2010; Tigga et al., 2014). CCPP is severe threat to goat population and their production performance in developing countries (Bascunana et al., 1994; Lorenzon et al., 2002) The serological and molecular prevalence of CCPP in the northern areas and various other region of the country have been previously reported by several researchers (Awan et al., 2010; Sadique et al., 2012; Peyraud et al., 2014; Wazir et al., 2016; Shah et al., 2016). The present study was designed to investigate the seroprevalence of CCPP in goat's population in Pakistan. The result of the present study is in coordination with the statements of various other scientists who studied the serologicalprevalence of CCPP caused by Mccp across the country (Peyraud et al., 2014) in international collaborative study showed the prevalence of Mccp as $2.7 \%$ and $44.2 \%$ through cELISA test in two districts of northern region of Pakistan. Similar test used by (Wazir et al., 2016) in 4 selected districts of Khyber Pakhtunkhwa and reported 3.91\% prevalence of Mccp and $8.52 \%$ prevalence of Mccp in various region of Punjab province of Pakistan was reported elsewhere (Shahzad et al., 2016). The results of the present study revealed that Mccp is present in Pakistan. However, these findings are in contrast with the previous reports (Shahzad et al., 2012; Sadique et al., 2012; Rahman et al., 2013) who reported that Mmc is responsible for CCPP in Pakistan. The findings of the present study are further justified by reports on the molecular prevalence of Mccp in Pakistan (Awan et al., 2010; Shah et al., 2016; Rahman et al., 2018; Ahmad et al., 2020). The results of the region wise distribution of the disease obtained in the present studywere $115(23 \%)$ in northern region followed by tribal region and central region $60(15 \%)$ and $52(13 \%)$ respectively. The highest frequency of the disease in the present study was recorded in northern region of 
Pakistan. This could be due to pastoral practices, extreme cold environmental condition, improper management system for large flock (up to 2000 animals in single flock), and movement of animals in winter season (last of October to start of April) for grazing. These factors may lead immunosuppression and make the goats susceptible for the proliferation of pathogenic Mycoplasma to cause infection. It has been reported that the flock size, management and production system of the small ruminants, carrier animals in the vicinity play a key role in extent of the disease in small ruminants (Sherif et al., 2012). Several other reports (Mekuria and Asmare, 2010; Shahzad et al., 2012; Ahmad et al., 2020) documented that the occurrence of the disease is more frequent in hilly areas and cold climatic condition.

The prevalence of CCPP being reported in 40 countries through various diagnostic techniques (MansoSilvan et al., 2011). The causative agent has recently being reported in Tajikistan and China (Chu et al., 2011). In Pakistan, Gilgit is bordering with China, and Chitral is has long boundary line with Afghanistan and adjacent to Tajikistan. The northern zone of Pakistan contain large population of small ruminants and additionally the entrance of sheep and goats from neighbouring countries could be a considerable threat of transmitting / carrying this transboundary disease (CCPP). The presence of Mccp is reported across the world in many countries however the frequency of occurrence is more in poor countries of Asia, Africa, Middle East and Europe (Woubit et al., 2004; Ozdemir et al., 2005; Manso-Silvan et al., 2011; Chu et al., 2011; Peyraud et al., 2014; OIE 2014). The climatic condition of the southern zone is hot humid with minimum rain fall and sandy terrestrial condition. During the winter season the nomads shift their animals to the southern region and thus the carrier animals disseminate the disease in the respective area. Secondly the non-availability of the fodder and harsh climatic condition of the southern region contribute to weakness of the health status of the animals and resultantly immunosuppression of the animals which becomes vulnerable to the infection. Similar findings were also reported that the intensity of the disease increases with cold climatic condition (Mekuria et al., 2008). Similarly, during the extensive movement of animals during Eid UI Adzha (Muslim Festival), seasonal movement of nomads and transportation of animals to markets round the year are hypothesized for the spread of the disease across the country. Similar trend of CCPP spreading is reported previously (Bekele et al., 2011; Sadique et al., 2012). Additionally, it has been observed that in Pakistan only a single specie vaccine based on Mmc is massively used and not provide any cross protection to Mccp which usually fails to control the CCPP outbreaks in the country.

In Pakistan most of the farmers keeps mixed herd of different sex, age, and breed. Both sex and ages of animals are equally susceptible to CCPP infection. In the present study the prevalence of the Mycoplasmosis was 119 (18.3\%) in female and 108 (16.6\%) in male. Previously, 33.03\% prevalence of Mycoplasmosis in female was reported compared to $29.2 \%$ in male (Sherif et al., 2012). Similar observations were also reported with the prevalence of CCPP in female animals was higher (39\%) in female animals compared to male (Shah et al., 2016). These results are also in accordance with the findings reported about $16.9 \%$ prevalence in female Spanish Ibex and $8.4 \%$ in male Ibex in Spain elsewhere (Verbisck et al., 2008). The increase prevalence of CCPP in female animals might be due to various factors which develop stress in animals including pregnancy, lactation, and oestrus cycle. The stress induce by these various factors weakens the immune status of the animals and pave the way for 
the proliferation of opportunistic Mycoplasma to cause infection in immune compromised animals (Blood et al., 2007). However, some researchers reported high prevalence in male $5.32 \%$ than $4.67 \%$ in female goats (Yousuf et al.,, 2012). Similarly, in Ethiopia prevalence of CCPP in female animals (6.66\%) was found lowered compared to bucks $24.08 \%$ (Regassa et al., 2010). Various other researchers from Ethiopia and Tanzania reported that sex does not play significant role in epidemiology of CCPP (Kusiluka et al., 2000; Hadush et al., 2009; Mekuria et al., 2010; Yousuf et al., 2012). The difference in prevalence rate of CCPP in male and female animals may be due to immune status of the animal, different in locality of sampling, male female ration in herd and biosecurity at herd level.

CCPP can affect goat's population at all stages of their life, however the increase morbidity and mortality are reported in lower age of goat'spopulation. In present study minimum prevalence was observed in kids $43(10.8 \%)$ compared to adult goats $184(20 \%)$. Our results agreed with the finding of high prevalence of CCPP $30 \%$ in adult goats (Regassa et al., 2010). Similarly, it has also been reported that goats at adult age are more affected than young stage elsewhere (Sherif et al., 2012). However, these finding are in contrast with reports documented previously from Pakistan (Shah et al., 2016; Shahzad et al., 2016). The increase percentage of mortality in young kids might be due the weak immune system of the kids who cannot fight with invading microbe affectively. The lymphoid organs develop when animal grows and strengthen the immune system of the host, and with the advancement of age the animals faces various pathogen in their life which further strong the immune system. Thus, the adultgoats are more capable to encounter the invading Mycoplasma effectively. Furthermore, the antibody can be detected in serum after the infection has been cleared (Rurangirwa et al., 1987).

\section{Declarations}

\section{Acknowledgment}

This research work was financially supported by the joint research project of The University of Agriculture, Peshawar, Pakistan and Sandia National Laboratories, New Mexico, USA under the Pak-US Science and Technology Cooperation Program, Phase 7, 2017. This program is supported and implemented by the National Academy of Sciences (NAS) in the U.S. and by the Higher Education Commission (HEC), Islamabad, Pakistan. We are also thankful to the Livestock \& Dairy Development (Extension) (L\&DD KPK), and Veterinary Research Institute, Peshawar for their help and support in sampling.

\section{Statement of Animal Rights}

This study was approved by the ethical committee of The University of Agriculture Peshawar. All experimental procedures was performed under the institutional guidelines and animal ethics.

\section{Conflict of interest}

The authors have no conflict of interest to disclose. 
4. Author's contribution: FA, FAK, and US designed and conceived the study. FA, FAK and AS carried out the research. FA, FAK, US analysed the data. FA and FAK wrote the manuscript. FAK and AS critically reviewed and revised the manuscript.

5. Consent for publication: All the authors showed agreement on the publication of this manuscript in this esteemed journal.

6. Data Availability: Data sharing not applicable to this article.

\section{References}

1. Ahmad, F., Khan., Khan, H., Anwar, F., Carson, B.D. and Sadique, U., 2020. The first isolation and molecular characterization of Mycoplasma capricolum subsp. capripneumoniae Pakistan strain: A causative agent of contagious caprine pleuropneumonia. J. Microbiol. Immunol. Infection. https://doi.org/10.1016/j.jmii.2020.06.002.

2. Awan, M.A., Abbas, F., Yasinzai, M., Nicholas, R.A. and Babar, S., 2010. First report on the molecular prevalence of Mycoplasma capricolum subspecies capripneumoniae (Mccp) in goats the cause of contagious caprine pleuropneumonia (CCPP) in Balochistan province of Pakistan. Mol. boil. Rep. 37, 3401-3406.

3. Awan, M.A., Abbas, F., Yasinzai, M., Nicholas, R.A.J. and Babar, S., 2009. Prevalence of Mycoplasma capricolum subsp. capricolum and Mycoplasma putrefaciens in goats in Pishin district of Balochistan. Pak. Vet. J. 29(4).

4. Ayling, R.D., Bashiruddin, S.E. and Nicholas, R.A.J., 2004. Mycoplasma species and related organisms isolated from ruminants in Britain between 1990 and 2000. Vet. Rec. 155(14), 413-416.

5. Bascuñana, C.R., Mattsson, J.G., Bölske, G. and Johansson KE., 1994. Characterization of the 16S rRNA genes from Mycoplasma sp. strain F38 and development of an identification system based on PCR. J. Bacteriol. 176(9), 2577-2586.

6. Bekele, T., Asfaw, Y., Gebre-Egziabeher, B. and Abebe, G., 2011. Seroprevalence of contagious caprine pleuropneumonia in Borana and Guji lowlands, Southern Ethiopia. Ethiopian Vet. J. 15(2).

7. Blood, D.C., Studdert, V.P. and Gay, C.C., 2007. Saunders Comprehensive Veterinary Dictionary, ( Elsevier.

8. Chazel, M., Tardy, F., Le, Grand, D., Calavas, D. and Poumarat, F., 2010. Mycoplasmoses of ruminants in France: recent data from the national surveillance network. BMC Vet. Res. 6(1), 32.

9. Chu, Y., Yan, X., Gao, P., Zhao, P. and He, Y., 2011. Molecular detection of a mixed infection of Goat pox virus, Orf virus, and Mycoplasma capricolum subsp. capripneumoniae in goats. J. Vet. Diag. Invest. 23(4), 786-789.

10. Cottew, G.S., Breard, A., DaMassa, A.J., Ernø, H. and Leach, R.H., 1987. Taxonomy of the Mycoplasma mycoides cluster. Israel J. med. sci. 23(6), 632. 
11. Economic Survey of Pakistan. 2017-18. Finance Division, Economic Advisors Wing, Ministry of Finance, Govt. of Pakistan, Islamabad 2, 20-40.

12. Fischer, A., Shapiro, B., Muriuki, C., Heller, M. and Schnee, C., 2012. The Origin of the 'Mycoplasma mycoides Cluster' Coincides with Domestication of Ruminants. PLoS ONE 7(4): e36150. doi:10.1371/journal.pone.0036150

13. Hadush, B., Eshetu, L., Mengistu, W. and Hailesilassie, M., 2009. Seroprevalence of contagious caprine pleuropneumonia in Kefta Humera, Alamata (Tigray) and Aba-'ala (Afar), Northern Ethiopia. Trop. Ani. Health prod. 41(5), S803-806.

14. Jores, J., Cynthia, B., Alain, B., Glenn, F.B. and Angie, C., 2020. Contagious Bovine and Caprine Pleuropneumonia: a research community's recommendations for the development of better vaccines. npj Vaccines (2020) 5:66; https://doi.org/10.1038/s41541-020-00214-2.

15. Khan, M.A., Sattar, A., Parveen, S., Rauf, A.M. and Niazi, N., 1989. Mycoplasmosis in Pakistan: A study of contagious caprine pleuropneumonia organism. Pak. J. Vet. Sci, 1(2), 47-50.

16. Kusiluka, L.J., Ojeniyi, B., Friis, N.F., Kazwala, R.R. and Kokotovic, B., 2000. Mycoplasmas isolated from the respiratory tract of cattle and goats in Tanzania. Acta Vet. Scand. 41(3), 299-309.

17. Lorenzon, S., Wesonga, H., Ygesu, L., Tekleghiorgis, T. and Maikano, Y., 2002. Genetic evolution of Mycoplasma capricolum subsp. capripneumoniae strains and molecular epidemiology of contagious caprine pleuropneumonia by sequencing of locus H2. Vet. Microbiol. 85(2), 111-123.

18. MacOwan, K.J. and Minette, J.E., 1976. A mycoplasma from acute contagious caprine pleuropneumonia in Kenya. Trop. Ani. Health prod. 8(1), 91-95.

19. Manso-Silván, L., Dupuy, V., Chu, Y. and Thiaucourt, F., 2011. Multi-locus sequence analysis of Mycoplasma capricolum subsp. capripneumoniae for the molecular epidemiology of contagious caprine pleuropneumonia. Vet. Res. 42(1), 86.

20. McMartin, D.A., MacOwan, K.J. and Swift, L.L., 1980. A century of classical contagious caprine pleuropneumonia: from original description to aetiology. British Vet. J. 136(5), 507-515.

21. Mekuria, S. and Asmare, K., 2010. Cross-sectional study on Contagious Caprine Pleuro Pneumonia in selected districts of sedentary and pastoral production systems in Southern Ethiopia. Trop. Ani. Health prod. 42(1), 65.

22. Mekuria, S., Zerihun, A., Gebre-Egziabher, B. and Tibbo, M., 2008. Participatory investigation of Contagious Caprine Pleuropneumonia (CCPP) in goats in the Hammer and Benna-Tsemay districts of southern Ethiopia. Trop. Ani. Health prod. 40(8), 571-582.

23. OIE. 2014. Contagious caprine pleuropneumonia. OIE Terrestrial Manual. Chapter 2.7.6. Office International Des Epizootics, Paris, France. 704-719.

24. Ozdemir, U., Ozdemir, E., March, J.B., Churchward, C. and Nicholas, R.A., 2005. Contagious PCR for the identification of Mycoplasma capricolum subsp. capripneumoniae, the causative agent of contagious caprine pleuropneumonia (CCPP). Vet. Microbiol. 104(1-2), 125-132.

25. Peyraud, A., Poumarat, F., Tardy, F., Manso-Silván, L. and Hamroev, K., 2014. An international collaborative study to determine the prevalence of contagious caprine pleuropneumonia by 
monoclonal antibody-based cELISA. BMC Vet. Res. 10(1), 48.

26. Rahman, S.U., Siddique, M., Hussain, I., Muhammad, K. and Rasool, M.H., 2003. Standardization of indirect haemagglutination test for monitoring Mycoplasma mycoides subspecies capri antibodies raised in rabbits and goats. Int. J. Agri. Biol. 5, 295-297.

27. Regassa, F., Netsere, M. and Tsertse, T., 2010. Sero-prevalence of contagious caprine pleuropneumonia in goat at selected woredas of Afar region. Ethiopian Vet. J. 14(1), 83-90.

28. Rurangirwa, F.R., McGuire, T.C., Musoke, A.J. and Kibor, A., 1987. Differentiation of F38 mycoplasmas causing contagious caprine pleuropneumonia with a growth-inhibiting monoclonal antibody. Inf. Immun. 55(12), 3219-3220.

29. Sadique, U., Chaudhry, Z.I., Younas, M., Anjum, A.A. and Hassan, Z.U., 2012. Molecular characterization of Contagious Caprine Pleuropneumonia (CCPP) in small ruminants of Khyber Pakhtunkhwa, Pakistan. J. Ani. Plant Sci. 22, 33-37.

30. Shah, M.K., Saddique, U., Ahmad, S., Iqbal, A. and Ali, A., 2017. Molecular Characterization of Local Isolates of Mycoplasma capricolum subsp. capripneumoniae in Goats (Capra hircus) of Khyber Pakhtunkhwa, Pakistan. Pak. Vet. J. 37(1).

31. Shahzad, W., Munir, R., Khan, M.S., Shakil, M. and lqbal, M., 2012. Characterization, molecular diagnosis and prevalence of caprine mycoplasmosis in different areas of Pakistan. Pak. J. Zool, 44(2).

32. Shahzad, W., Yaqoob, T., Mukhtar, N., Munir, R. and Ahmad, R., 2016. Sero-prevalence of Mycoplasma capricolum subsp. capripneumoniae in goats through cELISA in different districts of Punjab, Pakistan. J. Ani. Plant Sci. 26(4), 931-937.

33. Sherif, M., Addis, M. and Tefera, M., 2012. Contagious caprine pleuropneumonia: Serological survey in selected districts of Jijiga zone, Ethiopia. Asian J. Ani. Sci. 6(6), 309-315.

34. Srivastava, A.K., Meenowa, D., Barden, G., Salguero, F.J. and Churchward, C., 2010. Contagious caprine pleuropneumonia in Mauritius.

35. Thiaucourt, F. and Bölske, G., 1996. Contagious caprine pleuropneumonia and other pulmonary mycoplasmoses. Rev. Sci. Tech. Int. Epiz. 15, 1397-1414.

36. Tigga, M., Choudhary, B.K., Ghosh, R.C. and Malik, P., 2014. Mycoplasmosis: An emerging threat to developing livestock industry. Int. J. Adv. Res. 2(1), 558-564.

37. Verbisck-Bucker, G., González-Candela, M., Galián, J., Cubero-Pablo, M.J. and Martín-Atance, P., 2008. Epidemiology of Mycoplasma agalactiae infection in free-ranging Spanish ibex (Capra pyrenaica) in Andalusia, southern Spain. J. wildlife dis. 44(2), 369-380.

38. Wazir, I., Hussain, I., Khan, M.A., Ali, M.I. and Rahman, H.U., 2016. Sero-epidemiological Analysis of Contagious Caprine Pleuropneumonia through cELISA in Selected Districts of Khyber PakhtunkhwaPakistan. American Sci. Res. J. Engi. Tech. Sci. 26(3), 274-281.

39. Woubit, S., Lorenzon, S., Peyraud, A., Manso-Silvan, L. and Thiaucourt, F., 2004. A specific PCR for the identification of Mycoplasma capricolum subsp. capripneumoniae, the causative agent of contagious caprine pleuropneumonia (CCPP). Vet. Microbiol. 104(1-2), 125-132. 
40. Yousuf, E., Melaku, A. and Bogale, B., 2012. Seroprevalence of contagious caprine pleuropneumonia in Dire Dawa provisional administrative council, Eastern Ethiopia. J. Vet. Med. Ani. Health. 4(7), 9396.

\section{Tables}

Table.1 Sample collection for the serological prevalence of Mccp in goats of Khyber Pakhtunkhwa and northern areas of Pakistan.

\begin{tabular}{llllll} 
Area/zones of KP & \multicolumn{2}{l}{ Goats } & \multicolumn{3}{l}{} \\
\cline { 2 - 5 } & \multicolumn{2}{l}{ Young } & \multicolumn{2}{l}{ Adult } & \multicolumn{2}{l}{ Total } \\
\cline { 2 - 5 } & Buck & Doe & Buck & Doe \\
\hline Northern zone & 50 & 50 & 200 & 200 & 500 \\
\hline Central zone & 50 & 50 & 150 & 150 & 400 \\
\hline Tribal districts & 50 & 50 & 150 & 150 & 400 \\
\hline Total & 150 & 150 & 500 & 500 & 1300 \\
\hline
\end{tabular}

Young age: day 0-180; adult: age above 180 days

Table 2: Statistical analysis of data on Chi-square test showing Prevalence of Mccp in different zones of Khyber Pakhtunkhwa Pakistan and Northern Pakistan.

\begin{tabular}{|llllll|}
\hline Area & Mccp & \multicolumn{5}{c}{ Total No's of samples } & Chi-sq & P. value \\
\cline { 2 - 5 } & Positive sample & Negative samples & & 17.85 & 0.001 \\
\hline Northern region & 115 & 385 & 500 & & \\
Central region & 52 & 348 & 400 & & \\
\hline Tribal region & 60 & 340 & 400 & & \\
\hline Total & 227 & 1073 & 1300 & \\
\hline
\end{tabular}

Data revealed significant deference (Pख0.05) among the different zones and prevalence of Mccp.

Table 3: Statistical analysis by Chi-square test showing Gender Based sero-prevalence of CCPP in four zones of Khyber Pakhtunkhwa and Northern Pakistan. 


\begin{tabular}{|llllll|}
\hline Gender & Positive sample & Negative samples & Total samples & Chi-sq & P. value \\
\hline Male & 108 & 542 & 650 & 0.646 & 0.422 \\
\hline Female & 119 & 531 & 650 & & \\
\hline Total & 227 & 1073 & 1300 & & \\
\hline
\end{tabular}

Table 4: Age based seroprevalence of CCPP in goats of Khyber Pakhtunkhwa and Northern Pakistan.

\begin{tabular}{|llllll|}
\hline Age of animal & Positive sample & Negative samples & Total samples & Chi-sq & P. value \\
\hline Adult & 184 & 716 & 900 & 18.06 & 0.001 \\
\hline Young & 43 & 357 & 400 & & \\
\hline Total & 227 & 1073 & 1300 & & \\
\hline
\end{tabular}

Table: 5: Frequency of occurrence of Contagious caprine pleuropneumonia (CCPP) in goats flock from northern zone.

\begin{tabular}{|llll|}
\hline Name of District & Total No's of sample & Positive samples & \%age of positive sample \\
\hline Chitral & 120 & 29 & 24 \\
\hline Gilgit Baltistan & 135 & 37 & 27 \\
\hline Swat & 83 & 14 & 17 \\
\hline Buner & 71 & 14 & 20 \\
\hline Hazara & 91 & 21 & 23 \\
\hline Total & 500 & 115 & 23 \\
\hline
\end{tabular}

Table: 6: Frequency of occurrence of Contagious caprine pleuropneumonia (CCPP) in goats flock from central zone.

\begin{tabular}{|llll|}
\hline Name of District & Total No's of sample & Positive sample & \%age of positive sample \\
\hline Charsadda & 80 & 14 & 17.5 \\
\hline Mardan & 80 & 12 & 15 \\
\hline Swabi & 80 & 11 & 13.7 \\
\hline Peshawar & 80 & 6 & 7.5 \\
\hline Nowshera & 80 & 9 & 11.2 \\
\hline Total & 400 & 52 & 13 \\
\hline
\end{tabular}

Table: 7: Frequency of occurrence of Contagious caprine pleuropneumonia (CCPP) in goats flock from tribal zone. 


\begin{tabular}{|llll|}
\hline Name of District & Total No's of sample & Positive sample & \%age of positive sample \\
\hline Khyber & 150 & 21 & 14 \\
\hline Bajour & 150 & 28 & 18.6 \\
\hline Mohmand & 100 & 11 & 11 \\
\hline Total & 400 & 60 & 15 \\
\hline
\end{tabular}

\section{Figures}

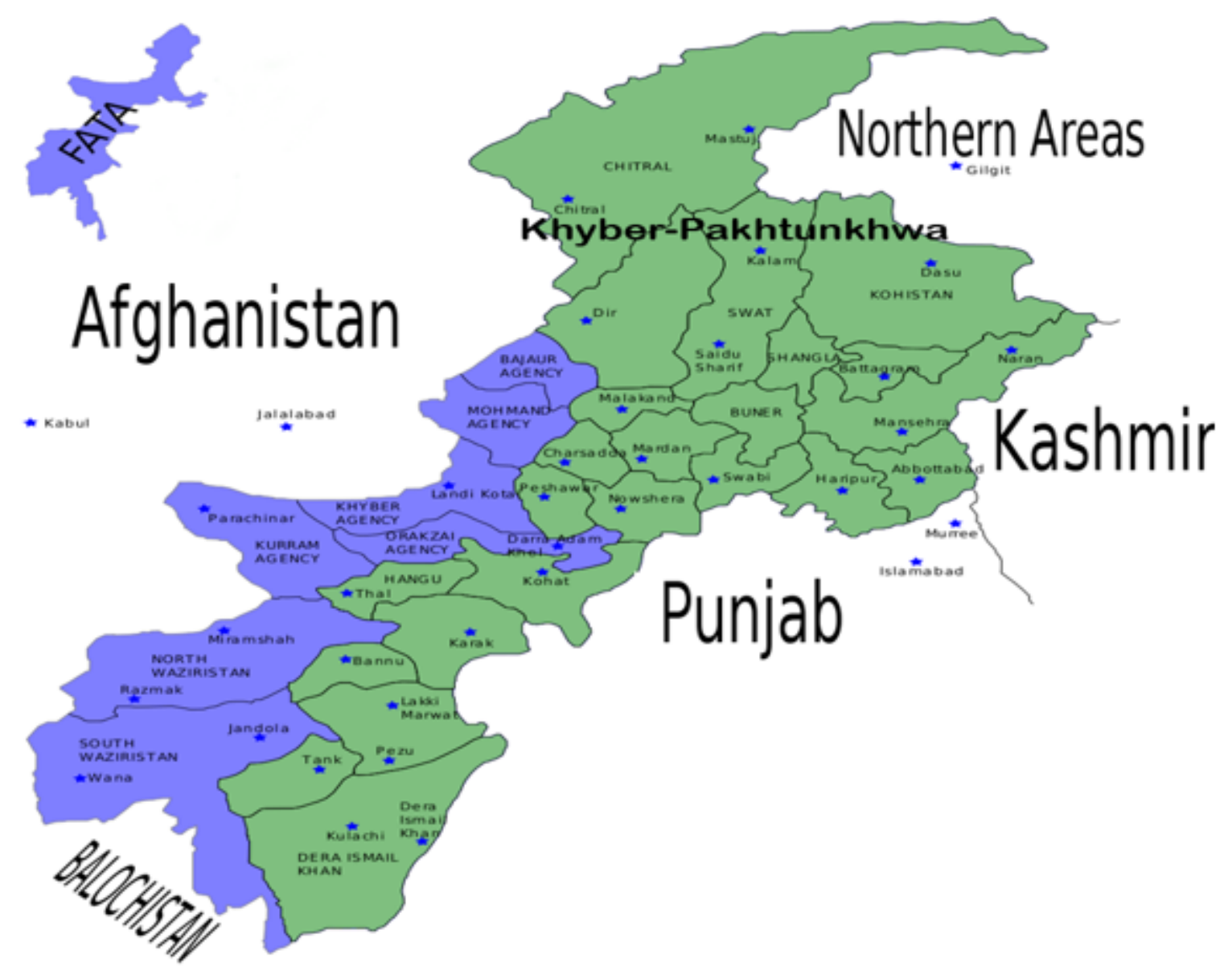

Figure 1

Map of Khyber Pakhtunkhwa (districts name in centre) and northern areas of Pakistan. 


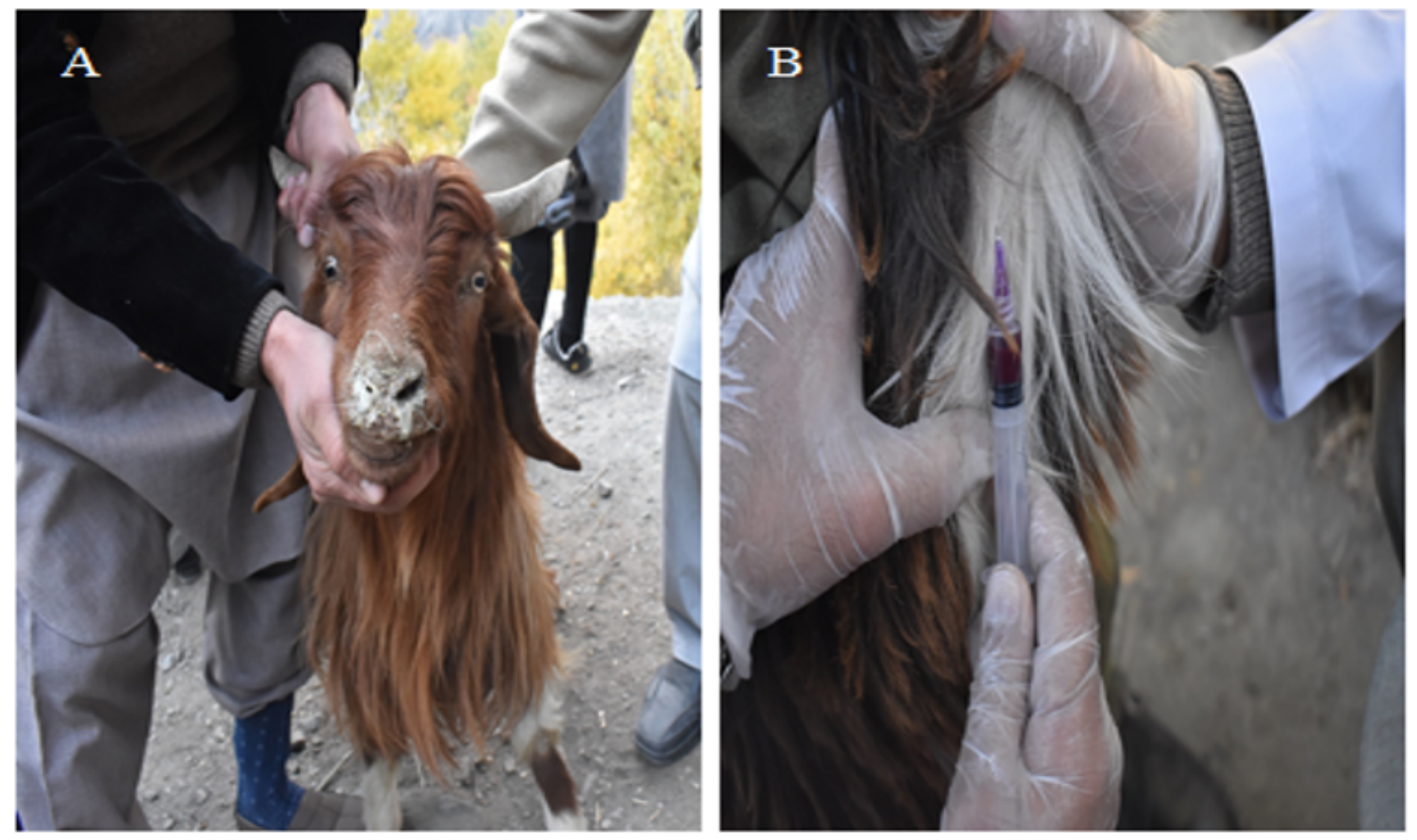

Figure 2

(A) Goat showing mucopurulent nasal discharges, painful cough suspected for contagious caprine pleuropneumonia; (B) Blood sample collection from jugular vein of goat. 